Home | Archives | About | Login | Submissions | Notify | Contact | Search

ES Home > Vol. 2, No. $2>$ Art. 19

Copyright (C) 1998 by The Resilience Alliance ${ }^{*}$

Leefers, L.A. and G.B. Castillo. 1998. Bridging the gap between economics and ecology. Conservation Ecology [online] 2(2): 19. Available from the Internet. URL: http://www.consecol.org/vol2/iss2/art19/

Insight, part of Special Feature on Sustainability and Resilience in Boreal Regions

\title{
Bridging the Gap Between Economics and Ecology
}

\author{
$\underline{\text { Larry A. Leefers and Gem B. Castillo }}$
}

\section{Michigan State University}

- Abstract

- Introduction

- A Step Toward Linking Ecology and Economics: Natural Resource Accounting

- Origin and Purpose of Natural Resource Accounting

- Case Studies

- SNA Satellite System for Integrated Environmental and Economic Accounting

- An Example of Physical Accounting: Michigan's Boreal Forest

- Conclusions

- Responses to This Article

- Literature Cited

\section{ABSTRACT}

Economics and ecology are often presented as opposing disciplines. Both fields have strengths and weaknesses. A new transdisciplinary field, ecological economics, attempts to bring together the strengths of both disciplines with a vision for a sustainable future. In this paper, we focus on one particular concept championed by ecological economists, natural capital. In particular, our interest is on the institutionalization of this concept through the United Nation's Satellite System for Integrated Environmental and Economic Accounting (SEEA). SEEA is an international convention that incorporates natural resource accounting as a complement to the traditional System of National Accounts (SNA). In the case of boreal forests, the stocks and flows of forest resources can be assessed to determine prospects for sustainability. To provide a context for how natural resource accounting may be applied to boreal forests, we review the origin and purpose of natural resource accounting, summarize several cases in which natural resource accounting has been applied, and present an example of stocks and flows from Michigan's (United States) boreal forest resources. Natural resource accounting work from Canada, Finland, Norway, and other countries with boreal forests should be compiled and analyzed to provide more insights regarding circumpolar forest conditions. 
KEY WORDS: boreal forest, circumpolar resources, degradation, depletion, ecological economics, Michigan, natural capital, natural resources accounting, SEEA, sustainability, United Nations Environment Programme, World Bank.

\section{NTRODUCTI ON}

Economics and ecology often receive two different responses from natural resources professionals. Economics, which deals with the allocation of scarce human-made and natural resources, is viewed unfavorably by many who are concerned about effects of society on the environment and natural resources. Ecology, which deals with nature's allocation of scarce resources, is more often viewed in a favorable light. Economics is burdened, in particular, by a misperception that it is synonymous with finance. That is, financial decisions (i.e., profit, the "bottom line", etc.) are confused with the much broader equity and efficiency concerns that provide the theoretical underpinning for economics. For many years, resource economists have addressed natural resource and environmental issues in theory and in practice. The most recent offshoot of these earlier efforts is the newly evolving field of ecological economics (Prugh 1995).

According to Costanza et al. (1997), ecological economics is a transdisciplinary field that focuses on the three linked goals of sustainability, fairness in distribution, and efficiency in allocation. As a result, ecological economists have more interest in a vision of the future, methods for analyzing problems in new ways, and institutions and instruments that are needed to implement this vision. The vision includes recognition that: (1) our planet is essentially a closed system in which our societies are subsystems; (2) a sustainable future exists for all species that is constrained by the global ecosystem; (3) we should be cautious and humble, given the many uncertainties that exist; and (4) our policies must become more proactive, with clearer thought about the interrelationships of the earth's subsystems. Costanza and Daly (1987) noted that neither economists nor ecologists were adequately addressing this vision, and that a new, integrated approach, ecological economics, was required.

The vision is ambitious, and several aspects (e.g., interspecies distribution of wealth and intergenerational equity) may be very difficult to achieve. Nonetheless, we can move forward in other cases. Specifically, a more formal recognition of the role of natural capital and its relationship to sustainability is needed (Prugh 1995). In the case of boreal forests, the stocks and flows of forest resources can be assessed to determine prospects for sustainability. This can be and is being accomplished through the emergence of natural resource accounting. To provide an understanding of how natural resource accounting may be applied to boreal forests, we first review the origin and purpose of natural resource accounting. Then we summarize several cases in which natural resource accounting has been applied and describe the United Nation's Satellite System for Integrated Environmental and Economic Accounting (SEEA). Finally, we present an example of stocks and flows from Michigan's (United States) boreal forest resources. Natural resource accounting work from Canada, Finland, Norway, and other countries with boreal forests should be examined to provide more insights regarding forest conditions; the major missing data for a circumpolar assessment may be from Russia.

\section{A STEP TOWARD LI NKI NG ECOLOGY AND ECONOMI CS: NATURAL RESOURCE ACCOUNTI NG}

Natural resource accounting is being adopted in many countries; some progress has been made in the United States, but there is significant Congressional resistance (United States Department of Commerce, Bureau of Economic Analysis 1994, Rylander 1996). There is growing recognition of the role of natural systems in providing consumptive natural resources, providing nonconsumptive natural resources, and assimilating waste material. However, the latter two roles receive little attention in aggregate measures of a nation's wealth (e.g., gross domestic product). In recent years, we have increased the monitoring of human use of natural systems, and we are now starting to institutionalize the monitoring into our accounting systems. 
The System of National Accounts (SNA), developed near the middle of this century, was structured to provide indicators of economic performance, a systematic approach for monitoring trends of economic growth, and data for policy analysis. The SNA, by design, does not include all economic activities or all the goods and services that contribute to human well-being; it was originally designed to provide information on economic production. However, we have witnessed rapid industrialization in the past 50 years, along with rapid population growth. These have led to concerns about welfare and sustainability. In particular, increasing production without consideration for the capacity of natural resources and the environment (e.g., as natural capital for production, waste sinks, etc.) will lead to deterioration and reduced future productivity. This concern is central to sustainable development. Systematically accounting for natural capital, especially if it is potentially at risk, has led to efforts to improve the SNA.

The conventional gross domestic product (GDP), the national accounting framework, has several problems with regard to natural resources and the environment. These problems include the following:

1) National accounts typically record depreciation of certain forms of human-made capital, such as facilities and equipment, but ignore forms of natural capital, such as the nation's stock of air, soil, water, nonrenewable resources, forests, and so on. Essential waste-assimilating and life-support roles are also ignored.

2) Natural and environmental resources are generally excluded from balance sheets and are only rarely assessed by environmental quality indicators.

3) Cleanup costs (e.g., to restore environmental assets) often fail to take into account cumulative environmental damages. For private firms, defensive environmental expenditures (measures undertaken to combat or control the negative externalities of production and consumption) mean less value added. In contrast, when such cleanup costs are incurred by the public sector or by households, national output increases.

4) Many goods and services provided by natural resources and the environment are not traded in markets, and therefore are not reflected in the SNA (Abaza 1992).

Thus, these shortcomings highlight the failure of GDP and similar measures to adequately reflect the many roles of natural resources and the environment in providing economic well-being. These oversights, if not addressed, have repercussions for current and future economic sustainability.

Traditional accounting systems have focused on GDP rather than net domestic product, in part due to the difficulty of evaluating depreciation. Similarly, measures of depletion and degradation are of concern for natural and environmental resources. Sustainability measures should reflect depreciation, depletion, and degradation.

Recognition of these problems led to the development of an environmentally adjusted net national product (EDP) and an environmentally adjusted net income (ENI). As envisioned, these revised measures would better reflect true income, improve recognition of environmental services, account for both human-made and natural capital deprecation, exclude categories of defensive environmental expenditures, and include damages resulting from economic activities. Environmental resource accounting (ERA) or natural resource accounting (NRA) arose from these early attempts. Abaza (1992) mentioned several milestones in the progress toward developing a natural resource and environmental accounting system. He noted that "[a]s far back as the early 1970s, various industrialized countries began to implement ERA systems while others considered what possible similar courses of action to take." In 1983, the United Nations Environment Programme (UNEP) convened a consultative meeting to explore progress made in ERA. Subsequent workshops were held, in collaboration with World Bank, in 1984, 1985, 1986 , and 1988.

Conceptually and practically, the purpose of environmental and natural resource accounting was to revise the SNA in order to incorporate measures of welfare and sustainability, including accounts for the depletion and degradation of natural resources (Bartelmus 1993, Markandya and Perrings 1993, Prudham and Lonergan 1993). The publication Wasting Assets (Repetto et al. 1989), by the World Resources Institute, ushered in another series of workshops sponsored by international organizations such as the World Bank and United Nations to tackle the issue of natural resource accounting. Bartelmus noted that the feasibility of incorporating natural resources and environmental accounting was first explored during these workshops jointly organized by UNEP and the World Bank. As a result, a consensus was reached that environmental accounting could be linked to the United Nations' 
SNA (Bartelmus 1993). This led to publication of the revised SNA (United Nations 1993) that incorporated the SEEA. In the updated SNA, new indicators were added to supplement GDP. GDP was adjusted to yield the environmentally adjusted gross domestic product (EDP) and, subsequently, the environmentally adjusted national income (ENI). The revised SNA, with more accurate information on the environmental facets of economic development, can assist in the formulation of policies for sustainable development.

These adjusted measures, like their progenitors, are calculated and based on current conditions regarding population, technology, policies, expenditures, consumption, and tastes/preferences. That is, they provide a static picture of sustainability, or if viewed over time, a comparative static one. There are also concerns regarding how accurately natural and environmental resource accounting prices reflect their actual contributions to human welfare. These conceptual and practical problems notwithstanding, the revised measures provide improved metrics for sustainable development.

In light of the revised SNA, Prudham and Lonergan (1993) suggested that natural resource accounting (NRA) has emerged from the need to better understand the relationship between human, social, and economic systems and those of natural systems. The latter functions as a source of consumptive market resources for economic production and for nonconsumptive, largely nonmarket resources, such as recreation sites and assimilative services to human populations. There is consensus among many academicians that maintaining the value of a country's natural system, as part of the total capital, is a necessary condition for enabling a country's population to be as economically well off in the future as in the present.

Much of the debate over the SNA has to do with conflicting goals of the system, namely to reflect both welfare and economic output. As long as welfare and economic output are viewed as mutually exclusive, the macroeconomic accounting system will fail to completely satisfy proponents of both total output and welfare accounting. However, many studies have addressed problems associated with the 1968 U.N. System of National Accounts.

\section{Case studies}

Several country studies on NRA have been completed over the past decade. A recent report (J. F. Vincent and J. H. Hartwick, unpublished report: "Accounting for the benefits of forest resources: concepts and experience. A report for the FAO Forestry Department. Harvard Institute of International Development," revised draft J uly 1997) provides an extensive compilation and review of NRA concepts and projects. Earlier papers by Peskin and Lutz (1990), Abaza (1992), and Prudham and Lonergan (1993) also review several country studies in more detail. Several of the most cited case studies for developing and industrialized countries are presented here. Frameworks for four developing countries (Indonesia, Mexico, Papua New Guinea, and the Philippines) are presented first, followed by frameworks for six industrialized countries (Japan, Canada, France, Australia, United States, and Finland) (adapted from Lutz 1993 and others).

\section{Indonesia}

Repetto et al. (1989) were the first to examine the effects of natural resources depletion (for petroleum, timber, and soil) on estimates of national income. Their approach involved compiling accounts of stocks and flows for resources over time. For each resource studied, stock at the beginning of the accounting period (e.g., a year) was listed along with unit price and their multiplicative product, the total value of the resource. Additions and/or removals from stocks were noted, as well as change in unit prices over the accounting period. At the end of each accounting period, final stock and final total value were calculated. Thus, the physical accounts were: closing stock = opening stock + additions - subtractions. And unit prices were used to transform stocks to values. This provided a basis for examining both physical and economic depletion.

\section{Mexico}

The case study in 1990 and 1991 by van Tongeren et al. (1993), of the U.N. Statistics Office, used the overall analytical framework of the SEEA. In essence, it examined the "feasibility of integrating economics and environmental data bases and analyses." Effects of oil extraction/depletion, deforestation and land use, and resource degradation were of particular interest. Prior to this study, oil reserves were treated as free goods and depletion was ignored. Separate accounts were identified for the environmental effects of oil extraction. The often- 
linked activities of deforestation and loss of forest land due to changing land use were also explored. The main steps in the study were: compilation of data on natural (physical) assets and degradation (e.g., erosion, pollution, solid wastes, etc.), valuation using two approaches (i.e., the discounted sum of future income streams vs. the cost of avoiding degradation/depletion), and comparison of different aggregate measures of economic performance. In the latter step, incrementally higher levels of depletion and degradation were quantified and reported.

\section{Papua New Guinea}

Bartelmus et al. $(1992,1993)$ undertook this study to test the feasibility of attempting integrated accounting "in a country at a relatively early stage of development [and] where actual environmental problems are still limited." The study was completed with limited resources and within a restricted time frame. As a result, only secondary data were used and the authors were able to use their framework to highlight some emerging environmental concerns. Agriculture, forestry, mining, and energy sectors were studied. An environmentally adjusted net domestic product was calculated, and two different methods for calculating the cost of depletion were tested (i.e., net price vs. user cost). The study also highlighted the importance of having strong physical databases for natural resource accounting; these were largely lacking in Papua New Guinea.

The Philippines

The Philippine Environment and Natural Resource Accounting Project (ENRAP) was an integration of other approaches, and was similar in some ways to the Indonesian experience (M. S. Delos Angeles, unpublished paper: "Integrating socio-economic and environmental policies: a cursory review." Paper presented at the IEMSD workshop, 1 August 1995, DENR, Quezon, City, Philippines). ENRAP is currently being institutionalized (IRG/ Edgevale/REECS 1996). The first phase of ENRAP focused on industry sectors such as forestry. Succeeding phases will focus on ecosystem types and resource scale (e.g., watersheds). This project is an excellent example of the direction others will follow.

NRA efforts in industrialized countries differ greatly, due to historic differences in the countries and the emphasis placed on the function of national accounts, namely, measuring economic performance and providing a coherent database to support economic policy, research, and modeling.

Japan

The Japanese developed an ERA that draws heavily from the concept of "Measures of economic welfare" developed by Nordhaus and Tobin (Abaza 1992). This method emphasized calculating a GNP adjusted by deducting pollution abatement expenditures and the cost of pollution. Abaza (1992), however, noted that the procedure was never institutionalized by Japan's national statistical office.

\section{Canada}

A macro-information system, called STRESS, was initiated in the late 1970s to facilitate the collection, storage, and manipulation of different types of environmental data. STRESS was based upon the process of human-caused and environmental stress and response, and related implications for human populations. Three distinct database programs have evolved from this base: (1) natural resources stocks and flows and their linkages with the economy; (2) state-of-the-environment databases; and (3) natural productivity databases. Prudham and Lonergan (1993) noted that there were two national-level resource accounting programs operating in Canada. The first linked income accounts (the SNA) to wealth accounts with biological, nonrenewable, and cycling systems resource accounts. The second, begun by Statistics Canada (1990), was more limited than the first and was intended to supplement the SNA. Specifically, it would produce satellite accounts for natural resources, and would value those natural assets for inclusion in the national balance sheets of the SNA. Vincent and Hartwick (1997) identified more recently published pilot studies focusing on forest resources in Canada, including timber and carbon sequestration.

\section{France}

According to Prudham and Lonergan (1993), the French system of resource accounts, called the patrimony 
accounts, is one of the most complex and comprehensive systems devised. This project was designed to analyze and describe the natural environment in its three basic dimensions: economic, social, and ecological. The original intention was to provide a database by which the aggregates of the SNA could be corrected for natural resource depletion. As the program progressed, however, it was recognized that subordinating to the SNA over-emphasized economic goals. Thus, the system has evolved to serve an array of purposes by providing various disciplines with a common environmental database in both qualitative and quantitative forms. The French system is thus designed to bridge the gap between the two major emphases of resource accounting. As reported by Peskin and Lutz (1993), development of these accounts has focused on selected sectors, due to modest funding levels.

\section{Australia}

Integrating environmental and economic accounts in Australia has been problematic (Young 1993). Environmental degradation and depletion of renewable resources at the national level appear minor compared to the value of the final goods and services produced in Australia's economy. This results, in part, because industries and services form a large part of the economy, and only about $6 \%$ of the work force is employed in renewable resources. Also, researchers have proposed the establishment of regional and sector-based accounts. One research finding is that incorporating changes in the value of mineral stocks in the national accounts has a far greater impact than resource degradation and exploitation of renewable resources, mainly because of price fluctuations and discoveries of reserves. A proposed alternative to resource accounts is the development of better environmental quality and personal welfare indicators.

\section{United States}

In the United States, accounting was limited historically to collecting data on pollution-abatement expenditures (Peskin and Lutz 1993). Later, a special study of the Chesapeake, reported by Grambsch et al. (1993), employed the accounting framework developed by Peskin (1989), in which a new sector, "nature," was added to the traditional sectors of industry, government, and households. Information in the accounts provided insight into the linkages between environmental and economic objectives. The authors pointed out that the environment and economy are far from being fully integrated in the case study accounts. The main obstacle for integration is the lack of information about the causal ties between the economy and the environment, and vice versa. However, current federal efforts related to natural resource accounting have been severely curtailed due to political pressure (Rylander 1996). Nonetheless, several national-level case studies have been completed for minerals, standing timber, and tourism (United States Department of Commerce, Bureau of Economic Analysis 1994, Okubo and Planting 1998).

\section{Finland}

Hoffren (1997) provided groundwork for later development of the government's official NRA system. Physical changes in Finland's forests, ecological indices, and recent monetary value trends are presented. The study was based on existing databases. Physical quantity accounts included forest area, data on biodiversity, wood material, carbon binding, air pollutants and acid deposition, and recreational information. Forest quality indicators were developed for ecosystems, species, and recreation. In addition, an overall indicator was developed. Monetary accounts covered wood and other forest products, forest growth, carbon binding, biodiversity protection, recreational values, cost of acid deposition, and sustainable income.

Thus, there are many existing approaches to environmental and natural resource accounting. Abaza (1992) categorized several of these approaches as follows: (1) identification and reclassification of environmental expenditures (Japan); (2) physical and resource accounting (France); (3) depreciation of marketed natural resources (Indonesia); and (4) full environmental and natural resource accounts with valuation (United Nations 1993, Hoffren 1997). The United Nation's SEEA is an integration of the various approaches developed so far.

\section{SNA satellite system for integrated environmental and economic accounting}

The SEEA is an integration of various experiences in environmental accounting (for details, see United Nations 1993). It encompasses natural resource accounting, monetary satellite accounting, and welfare-oriented accounting. Major objectives are (1) compilation of a set of physical accounts with linkages to monetary accounts and balance sheets; (2) separation of traditionally aggregated stocks and flows to identify certain environmental 
relationships, primarily expenditures on abatement, as well as defensive or mitigative measures; (3) completion of monetary accounts for both depletion and degradation due to anthropogenic causes; (4) extension of the concept of capital to include natural assets; and (5) adjustment of accounting identities (Bartelmus 1993). For those concerned with the circumpolar resources of the boreal forests, the SEEA provides a framework for assessing sustainability. In particular, it provides a framework for examining physical stocks and flows of forest resources and their monetary consequences.

The accounting process includes physical accounting (e.g., Materials-Energy Balance, analyzing material flow between environment and economy; Framework for the Development of Environmental Statistics, measuring the emission of certain residuals of economic activities and their impact on the quality of environment media; and NRA, which complements the Materials-Energy Balance approach), monetary accounting (usually market values and provision-cost), and valuation of natural assets (using market and nonmarket valuation methods). In many cases, even the first part (physical accounting) of the accounting is difficult. In the following section, we illustrate this first step in the context of Michigan's boreal forest.

\section{An example of physical accounting: Michigan's boreal forest}

Michigan is located in the north-central United States and has a northern border with Canada, a country with extensive boreal forests. In Michigan, there are 771,000 ha of boreal, lowland conifer forests (defined here as forest types: black spruce, Picea mariana; northern white cedar, Thuja occidentalis; and tamarack, Larix laricina). Traditionally, we have focused on the flow of resources from our forests, with recognition of the importance of sustainability. However, we have done little to assess that sustainability across forest types and owners. A NRA framework lends itself to closer monitoring of the sustainability of our forest use.

In physical accounting, we start with an opening stock and add net changes (additions such as growth and plantation development minus reductions such as harvest, wastes, mortality, and land conversion) to that stock to get a closing stock; this becomes the opening stock for the following year. The value of the flow and the stock can be assessed with different methods (not applied in this example). The physical stocks and flows provide insights regarding forest conditions, whereas the monetary accounts inform policy makers about the role of forest resources in the country's economy (Hoffren 1997).

With appropriate data and models, we can also examine implications regarding future sustainability of forest resources (Leefers et al. 1997). Although NRA is pursued as an ex post analysis, it may also have utility in ex ante analyses, particularly where depletion concerns exist and where inventories are only completed periodically. In Michigan, these boreal forest resources are not heavily utilized by forest products industries. We estimate that current harvests (1995) are $1.7 \times 10^{5} \mathrm{~m}^{3}$ (6.1 million cubic feet) annually in these types in Michigan, and the inventory surpasses $34.7 \times 10^{6} \mathrm{~m}^{3}$ (1,225 million cubic feet) (J. M. Vasievich, USDA Forest Service, North Central Forest Experiment Station, personal communication). Thus, $<0.5 \%$ of our inventory is currently harvested. We project that this harvest rate can be approximately doubled and the slow-growing forest inventory can still be maintained for the next 25 years. Current harvest rates would actually lead to an increase in stocks to $39.8 \times 10^{6}$ $\mathrm{m}^{3}$ (1,406 million cubic feet) by 2020 . Traditionally, we focus our analysis on sustaining the flow of resources rather than sustaining or growing the stock of our resources. NRA causes us to consider both, in physical and monetary terms.

Although it appears that Michigan's boreal, lowland conifer forest resources may be managed without depletion, given current harvest levels, many questions remain regarding what to count and how to count. For example, the SEEA guidelines do not include plantations. How are set-asides or protected areas to be treated? And in the United States, many owners are involved in forestry practices in which one owner's resources are depleted while another's increase. The net positive result may mask underlying problems. Valuation problems also exist. As we expand beyond market goods and services, less is known about economic values of forest resources. Nonetheless, the systematic approach for physical accounting, monetary accounting, and valuation of natural assets provides an important framework for examining sustainability.

\section{CONCLUSI ONS}


The current SNA does not adequately reflect the depletion and degradation of natural resources and the environment. For example, defensive expenditures incurred by industry are treated as intermediate expenditures, whereas those undertaken by households and governments are generally treated as final expenditures. In this latter context, defensive expenditures are treated as economic growth. Although depreciation of human-made capital is deducted from gross national product to arrive at net national product, no allowance is made for the depletion or degradation of natural resources and the environment (El Serafy and Lutz 1989). Part of this may be conceptually viewed as the depreciation of natural capital. Finally, many of the goods and services provided by the environment and natural resources are not traded in the markets, and therefore are not reflected in the SNA.

As we have shown, the NRA framework has potential for use in ex post and ex ante analyses. Ex post analysis is consistent with the monitoring/accounting approach proposed by SEEA. However, where threats of depletion are a concern (as may be the case for some boreal forest resources) and inventories are infrequent, ex ante analyses such as the one presented for Michigan may be appropriate. Moreover, NRA refocuses our traditional analyses to place more emphasis on the condition of our stock, our natural capital. As a result, NRA helps to bridge the gap between economics and ecology.

As a next step for organizations concerned about the sustainability of boreal forests (e.g., The Beijer International Institute of Ecological Economics in Sweden), researchers might compile existing NRA work from Canada, Finland, Norway, and other countries; the major missing data for a circumpolar assessment may be from Russia. By compiling this information, consistencies and inconsistencies between countries may be noted and further studies undertaken to provide an improved picture of the boreal forests from an ecological and economic perspective.

\section{RESPONSES TO THIS ARTI CLE}

Responses to this article are invited. If accepted for publication, your response will be hyperlinked to the article. To submit a comment, follow this link. To read comments already accepted, follow this link.

\section{LITERATURE CITED}

Abaza, H., editor. 1992. The present state of environmental and resource accounting and its potential application in developing countries. UN Environmental Economics Series Number 1. United Nations, New York, New York, USA.

Bartelmus, P. 1993. Environmental statistics and accounting. Chapter II in A. Markandya and C. Costanza, editors. Environmental accounting: a review of the current debate. United Nations Environment Programme (UNEP), Environment And Economics Unit (EEU), Environmental Economics Series Paper Number 8. Harvard Institute for International Development, Cambridge, MA, USA.

Bartelmus, P., E. Lutz, and S. Schweinfest. 1992. Integrated environmental and economic accounting: a case study for Papua New Guinea. Environment Working Paper Number 54. The World Bank, Washington, D.C., USA.

Bartelmus, P., E. Lutz, and S. Schweinfest. 1993. Integrated environmental and economic accounting: a case study for Papua New Guinea. Pages 108-143 in E. Lutz, editor. Toward improved accounting for the environment. A UN Stat-World Bank Symposium, IBRD-World Bank, New York, New York, USA.

Costanza, R., J . Cumberland, H. Daly, R. Goodland, and R. Norgaard. 1997. An introduction to ecological economics. St. Lucie Press, Boca Raton, Florida, USA.

Costanza, R., and H. E. Daly. 1987. Toward an ecological economics. Ecological Modelling 38(September): 1-7. 
EI Serafy, S., and E. Lutz. 1989. Environmental and resource accounting: an overview. Pages 1-7 in Y. J. Ahmad, S. El Serafy, and E. Lutz, editors. Environmental accounting for sustainable development, The World Bank, Washington, D.C., USA.

Grambsch, A. E., R. G. Michaels, and H. M. Peskin. 1993. Taking stock of nature: environmental accounting for Chesapeake Bay. Pages 184-197 in E. Lutz, editor. Toward improved accounting for the environment. A UN Stat-World Bank Symposium, IBRD-World Bank, New York, New York, USA.

Hoffren, J . 1997. Finnish forest resource accounting and ecological sustainability. Tutkimuksia Forskningsrapporter Research Report 224, Helsinki, Finland.

I RG/ Edgevale/ REECS. 1996. ENRAP (Environmental and Natural Resources Accounting Project) III main report. Report prepared for the Department of Environment and Natural Resources and the United States Agency for International Development, International Resources Group, Washington, D.C.; Edgevale Associates, Virginia, USA; and Resources, Environment and Economics Center for Studies, Quezon City, Philippines.

Leefers, L. A., K. Potter-Witter, and J. M. Vasievich. 1997. Modeling the multiple-owner timber supply problem in the Lake States. Pages 356-361 in Proceedings of the 1996 Society of American Foresters Convention, Albuquerque, New Mexico, November 9-13, Bethesda, Maryland, USA.

Lutz, E. 1993. Toward improved accounting for environment: an overview. Pages 1-14 in E. Lutz, editor. Toward improved accounting for the environment. A UN Stat-World Bank Symposium, IBRD-World Bank, New York, New York, USA.

Markandya , A., and C. Perrings. 1993. Accounting for an ecologically sustainable development: a summary. Chapter I in A. Markandya and C. Costanza, editors. Environmental accounting: a review of the current debate. United Nations Environment Programme (UNEP), Environment And Economics Unit (EEU), Environmental Economics Series Paper Number 8. Harvard Institute for International Development, USA.

Okubo, S., and M. A. Planting. 1998. U.S. travel and tourism satellite accounts for 1992. Survey of Current Business 78(7):8-22.

Peskin, H. 1989. Environmental and non-market accounting in developing countries. Pages 59-64 in Y. J. Ahmad, S. El Serafy, and E. Lutz, editors. Environmental accounting for sustainable development. The World Bank, Washington, D.C., USA.

Peskin, H. M., and E. Lutz. 1990. A survey of resource and environmental accounting in industrialized countries. Environment Working Paper Number 37. The World Bank, Washington, D.C., USA.

Peskin, H. M., and E. Lutz. 1993. A survey of resource and environmental accounting approaches in industrialized countries. Pages 144-176 in E. Lutz, editor. Toward improved accounting for the environment. A UN Stat-World Bank Symposium, IBRD-World Bank, New York, New York, USA.

Prudham, W. S., and S. Lonergan. 1993. Natural resource accounting (I): a review of existing frameworks. Canadian J ournal of Regional Science 16(3): 363-386.

Prugh, T. 1995. Natural capital and human survival. International Society of Ecological Economics Press, Solomons, New York, USA.

Repetto, R., W. Magrath, M. Well, C. Beer, and F. Rossini. 1989. Wasting assets: natural resources in the national income accounts. World Resources Institute, Washington, D.C., USA.

Rylander, J. C. 1996. Accounting for nature: a look at attempts to fashion a "green GDP." Renewable Resources Journal 14(2):8-13. 
Statistics Canada. 1990. A framework for environmental statistics. (Draft). Environment and Natural Resource Section, Statistics Canada, Ottawa, ON, Canada.

United Nations. 1993. Integrated environmental and economic accounting: interim version. Studies in Methods, Handbook of National Accounting, Series F, Number 61. United Nations Publication, New York, New York, USA.

United States Department of Commerce, Bureau of Economic Analysis. 1994. Integrated economic and environmental satellite accounts. Survey of Current Business 74(4): 33-49.

van Tongeren, J ., S. Schweinfest, E. Lutz, M. Gomez Luna, and G. Martin. 1993. Integrated environmental accounting: a case study for Mexico. Pages 85-107 in E. Lutz, editor. Toward improved accounting for the environment. A UN Stat-World Bank Symposium, IBRD-World Bank, New York, New York, USA.

Young, M. 1993. Natural resource accounting: some Australian experience and observations. Pages 177-183 in E. Lutz, editor. Toward improved accounting for the environment. A UN Stat-World Bank Symposium, IBRD-World Bank, New York, New York, USA.

\section{Address of Correspondent:}

Larry A. Leefers

Department of Forestry

Michigan State University

126 Natural Resources Bldg.

East Lansing, MI 48424

USA

Phone: (517) 355-0097

Fax: (517) 432-1143

leefers@pilot.msu.edu

*The copyright to this article passed from the Ecological Society of America to the Resilience Alliance on 1 January 2000. 